\title{
Emprego da sondagem elétrica vertical integrada às análises químicas e microbiológicas no diagnóstico preliminar da contaminação do solo e da água subterrânea no cemitério municipal da cidade de Rio Claro (SP)
}

\author{
Use of the vertical electrical survey integrated to the chemical \\ and microbiological analyzes in the preliminary diagnosis of soil and \\ groundwater contamination in the Rio Claro city (SP) municipal cemetery \\ Fernanda Vieira Xavier', Walter Malagutti Filho², \\ Robson Willians da Costa Silva ${ }^{3}$, César Augusto Moreira ${ }^{4}$
}

\begin{abstract}
RESUMO
Necrochorume é um efluente gerado a partir da decomposição de corpos. Em cemitérios, a principal causa de poluição subsuperficial é a sua percolação, que altera significativamente o solo, impedindo-o de realizar suas funções naturais. Particularmente no Brasil, pela falta de planejamento consequente do histórico cultural, os cemitérios se localizam totalmente integrados à malha urbana, representando um problema de saúde pública. O risco de contaminação está associado à presença de elementos, como compostos nitrogenados, metais pesados, vírus e bactérias, com riscos inerentes à saúde humana. Na literatura, esses contaminantes têm sido constantemente identificados no ambiente geológico a partir de resultados analíticos de água e solo quando comparados a uma área não impactada. A presente pesquisa objetivou investigar eventuais alterações no meio físico subsuperficial do cemitério municipal da cidade de Rio Claro, São Paulo, por meio dos resultados analíticos dos poços, apoiados por dados obtidos da técnica geofísica da sondagem elétrica vertical (SEV). Os resultados apontaram boa correlação com a evolução espacial e temporal da ocupação do cemitério ao longo de sua história.
\end{abstract}

Palavras-chave: necrochorume; contaminantes; eletrorresistividade.

\begin{abstract}
Putrefative liquid is an effluent generated from the decomposition of bodies. In cemeteries, the leading cause of subsurface pollution is the liquefaction products percolation, which substantially alter the physicalchemical and biological characteristics of the soil. In Brazil, due to the lack of consistent planning due to cultural history, cemeteries are fully integrated into urban areas, which can be a public health problem. The risk of contamination is associated with the presence of elements such as nitrogen compounds, heavy metals, viruses and bacteria, with risks to human health. In the literature, these contaminants have been consistently identified in the geological environment through analytical results of water and soil compared to non affected areas. This research aimed to investigate possible changes in the subsurface physical environment of the Rio Claro city (São Paulo, Brazil) municipal cemetery, through the analytical results of the wells, supported by data obtained from the geophysical technique of vertical electrical sounding (VES). The results showed good correlation with the spatial and temporal evolution of the occupation of the cemetery throughout its history.
\end{abstract}

Keywords: putrefative liquid; contaminants; electrical resistivity.

\footnotetext{
Geógrafa. Doutora em Geociências e Meio Ambiente, Universidade Estadual Paulista "Júlio de Mesquita Filho" (UNESP) - Rio Claro (SP), Brasil. ${ }^{2}$ Geólogo. Doutor em Geociências e Meio Ambiente, UNESP - Rio Claro (SP), Brasil. BEngenheiro ambiental. Doutor em Ciências, Universidade de São Paulo (USP) - São Paulo (SP), Brasil. ${ }^{4}$ Geólogo. Doutor em Geociências e Meio Ambiente, UNESP - Rio Claro (SP), Brasil.

Endereço para correspondência: Fernanda Vieira Xavier - Travessa Cururu, 66, casa 6 - Cavalhada - 78200-000 - Cáceres (MT), Brasil - E-mail: ferx.unesp@gmail.com Recebido: 22/07/15 - Aceito: 06/02/17 - Reg. ABES: 152375
} 


\section{INTRODUÇÃO}

Em áreas de cemitério, a principal causa de poluição subsuperficial, de acordo com Dent \& Knight (1995), Pacheco et al. (1991), Marinho (1998), Silva (1998), Matos (2001) e Rezende (2005), é a percolação do necrochorume, efluente gerado a partir da decomposição dos corpos. Em termos físico-químicos, esse efluente apresenta, na sua composição, aproximadamente $60 \%$ de água, $30 \%$ de sais minerais e $10 \%$ de substâncias orgânicas; viscosidade maior que a água; densidade de $1,23 \mathrm{~g} / \mathrm{cm}^{3}$; e pH entre 5 e 9 à temperatura de 23 a $28^{\circ} \mathrm{C}$. Segundo Dent \& Knight (1995), tem como características a cor negra, mau cheiro e elevada demanda bioquímica de oxigênio (DBO).

Quando em estado de putrefação, que é a destruição dos tecidos do corpo por ação das bactérias e enzimas, o resultado é a dissolução gradual dos tecidos em gases, líquidos e sais. Os gases produzidos são: $\mathrm{H}_{2} \mathrm{~S}$ (sulfeto de hidrogênio ou ácido sulfídrico, quando dissolvido em água), $\mathrm{CH}_{4}$ (gás metano), $\mathrm{NH}_{3}$ (amônia), $\mathrm{CO}_{2}$ (gás carbônico) e $\mathrm{H}_{2}$ (gás hidrogênio). $\mathrm{O}$ odor é causado por alguns desses gases e por pequena quantidade de mercaptana, substância que contém sulfeto de hidrogênio ligado a carbono saturado (POUNDER, 1995).

Segundo Üçisik e Rushbrook (1998) e Silva (1995), se considerar um cadáver adulto de $70 \mathrm{~kg}$, um líquido é liberado intermitentemente em quantidades equivalentes a $0,60 \mathrm{~L}^{\mathrm{kg}}{ }^{-1}$. Essa é a relação necrochorume/massa corpórea para um adulto desse peso, aproximadamente. O tempo de composição do corpo da mulher pode variar entre um quarto e dois terços da do homem (DENT \& KNIGHT, 2007).

Esse líquido, mais viscoso que a água, mas nela bastante solúvel, é rico em sais minerais e substâncias orgânicas degradáveis, de coloração castanho-acinzentada, polimerizável, de cheiro acre e fétido e com grau variado de patogenicidade (SILVA, 1998; MATOS, 2001). Contém diversas diaminas, mas as mais preponderantes são as mais tóxicas, entre as quais: a putrescina $\left(1,4\right.$ Butanodiamina $\left.-\mathrm{C}_{4} \mathrm{H}_{12} \mathrm{~N}_{2}\right) \mathrm{e}$ a cadaverina (1,5 Pentanodiamina $-\mathrm{C}_{5} \mathrm{H}_{14} \mathrm{~N}_{2}$ ), que podem ser degradadas, gerando amônio $\left(\mathrm{NH}_{4}{ }^{+}\right)$(SILVA, 1998). Além da eliminação do necrochorume pelos corpos, outros poluentes, não menos importantes, levantados por Silva $(1995 ; 1998)$, devem ser lembrados, como os óxidos metálicos ( $\mathrm{Ti}, \mathrm{Cr}, \mathrm{Cd}, \mathrm{Pb}, \mathrm{Fe}, \mathrm{Mn}, \mathrm{Hg}$, Ni e outros) lixiviados dos adereços diversos das urnas mortuárias, acessórios de embalsamamento, dentre outros.

Matos \& Pacheco (2002) ressaltam que, devido à heterogeneidade da composição química do necrochorume, encontram-se números elevados de bactérias degradadoras de matéria orgânica (bactérias heterotróficas), de proteínas (bactérias proteolíticas) e lipídios (bactérias lipolíticas). Encontram-se também bactérias que são normalmente excretadas por humanos (e animais), pois vivem nos seus tratos intestinais, como Escherichia coli, Enterobacter, Klebsiella e Citrobacter (as quatro formam o grupo coliforme total) e Streptococcus faecalis, que, ao serem ingeridas, provocam diarreias e dores abdominais; e microrganismos patogênicos como Clostridium perfringes e Clostridium welchii, que causam tétano, gangrena gasosa e intoxicação alimentar; Salmonella typhi, que causa a febre tifoide; Salmonella paratyphi, que causa febre paratifoide; Shigella, que causa a disenteria bacilar; e o vírus da hepatite A.

Vale ressaltar que o meio subterrâneo envolve o meio poroso do solo e a água nele presente. Assim, além da problemática ligada à contaminação de aquíferos, a descarga de resíduos de toda e qualquer espécie no meio poroso do solo pode causar alterações significativas, que o impede de exercer suas funções ecossistêmicas.

Dent e Knight (2007) ressaltam que os produtos de decomposição podem ultrapassar os limites do cemitério, dependendo do grau de acumulação existente, dos caminhos de escoamento da água, da localização do cemitério e de muitos outros fatores.

Autores como Pacheco et al. (1991), Jonker \& Olivier (2012), Charzynski, Bednarek e Zołnowska (2010), Spongberg \& Becks (2000) e Üçisik \& Rushbrook (1998) discorreram sobre a contaminação subsuperficial em áreas de cemitério os últimos anos, porém, os impactos causados aos solos por tais compostos não têm sido muito explorados. De acordo com Amuno \& Amuno (2014), apesar da escassez de literatura sobre solos impactados por cemitérios, alguns autores iniciaram as abordagens nessa temática, como Spongberg \& Becks (2000) e Jonker \& Olivier (2012), apontando importantes alterações pela putrefação humana na química do solo, com alterações significativas no $\mathrm{pH}$, na condutividade elétrica, e elevações significativas de compostos amoniacais.

Spongberg \& Becks (2000) estudaram um cemitério em Ohio, Estados Unidos, e apontaram os produtos contaminantes gerados: produtos químicos venenosos derivados de práticas funenárias, como arsênio e mercúrio; formaldeído; vernizes, selantes e conservantes utilizados em caixões de madeira; chumbo, zinco, cobre e aço de caixões de metal. Concluíram que certos metais podem se acumular em profundidade em cemitérios.

Matos \& Pacheco (2002) avaliaram a ocorrência e o transporte de microrganismos no aquífero freático do cemitério Vila Nova Cachoeirinha, município de São Paulo. As amostras de água indicaram, principalmente, bactérias heterotróficas, bactérias proteolíticas $\mathrm{e}$ clostrídios sulfito-redutores. Também atestaram a mobilidade de vírus e bactérias a algumas dezenas de metros em subsuperfície no cemitério.

Zychowski \& Bryndal (2015) realizaram uma revisão completa acerca dos resultados de investigações sobre contaminação associadas à presença, quantidade e qualidade de microrganismos em cemitérios de várias regiões do mundo.

É conveniente considerar o histórico de crescimento dos cemitérios com os impactos ambientais objetivando correlacionar as áreas alteradas físico-quimicamente com os locais de sepultamentos mais antigos. Parte-se do pressuposto que o potencial de alteração no meio 
exista principalmente nos cemitérios mais antigos e nos locais mais antigos dentro de um determinado cemitério. Porém, a prática operacional de sepultamentos afeta significativamente estudos quantitativos, pois a deposição dos restos mortais ocorre variadamente no tempo e no espaço dentro de um cemitério. Sepultamentos ocorrem em partes muito diferentes dos cemitérios em épocas diferentes.

Assim, o presente trabalho teve como objetivo subsidiar o diagnóstico da contaminação em subsuperfície, na área do cemitério centenário São João Batista, em Rio Claro, São Paulo; e por meio de análises físico-químicas e biológicas do solo e da água subterrânea, comprovar que as áreas mais antigas de sepultamento apresentam concentrações mais elevadas de contaminantes, demonstrando a importância de se analisar o aspecto histórico/temporal em áreas cemiteriais.

\section{METODOLOGIA}

\section{Caracterização da área de estudo}

O cemitério São João Batista é o principal cemitério da cidade de Rio Claro, São Paulo. Recebeu seus primeiros sepultamentos a partir de 1875, de forma irregular e, a princípio, localizava-se afastado da região do vilarejo. Porém, com o crescimento desordenado, hoje o cemitério encontra-se totalmente integrado à malha urbana, e em área central da cidade (Figura 1).

Atualmente, sua capacidade está esgotada, porém, ainda está ativo e os jazigos familiares são reutilizados após aproximadamente dois anos do último sepultamento, com média de 90 sepultamentos por mês.

A área de estudo localiza-se no domínio hidrogeológico de bacias sedimentares representado por depósitos do Quaternário e Terciário. Possui como característica solo predominantemente arenoso e com alta permeabilidade, com comportamento de "aquífero poroso", de acordo com Zaine (1994). Em termos geológicos locais, a área situa-se na faixa de ocorrência da Formação Rio Claro, caracterizada por fraca litificação e profunda alteração pedogenética, domínio de litotipos arenosos, esbranquiçados amarelados e avermelhados, variando de areia fina a grossa, com intercalação de camadas de conglomerados e de sedimentos argilosos. Sua espessura máxima é da ordem de $40 \mathrm{~m}$, predominando valores entre 25 e $30 \mathrm{~m}$. O problema reside na facilidade de percolação de compostos diversos pela alta permeabilidade/ porosidade subsuperficial na área do cemitério.

\section{Sondagem elétrica vertical}

Com a finalidade de se conhecer a profundidade do lençol freático na área do cemitério e elaborar o mapa potenciométrico, foi empregado

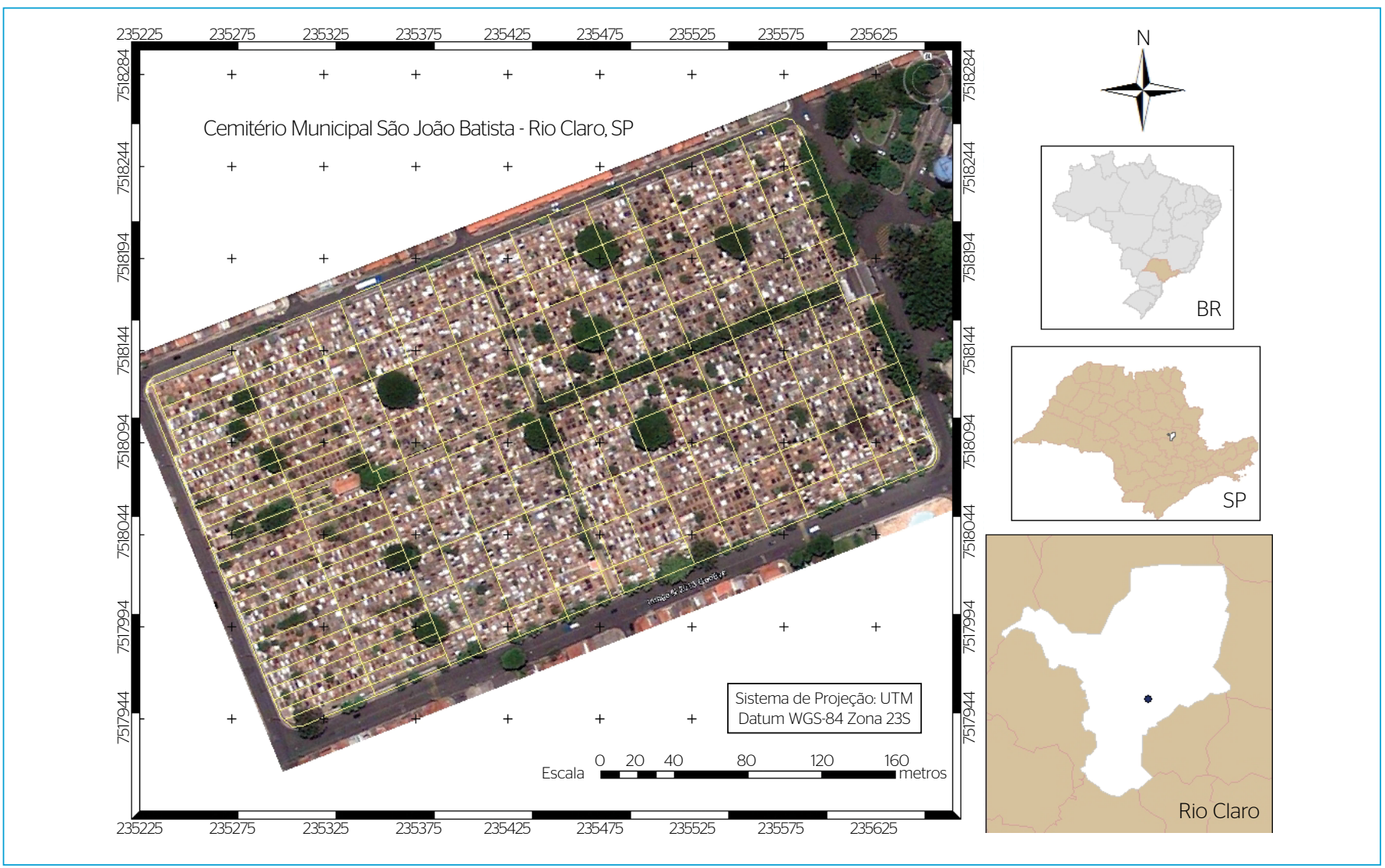

Figura 1 - Localização do Cemitério São João Batista, Rio Claro, São Paulo. 
o método geofísico da eletrorresistividade, a partir da técnica da sondagem elétrica vertical (SEV), cujo princípio consiste nas análises e interpretações das respostas do campo elétrico gerado no subsolo, que varia em diferentes profundidades conforme as condições geológico-geotécnicas e hidrogeológicas do local. Essa variação se reflete nos valores de resistividades dos materiais geológicos em subsuperfície. O método baseia-se na emissão de corrente elétrica no meio físico, por meio de eletrodos, controlada por um equipamento apropriado denominado resistivímetro. A diferença de potencial $(\Delta V)$ gerada pela passagem da corrente $(I)$ emitida pode ser medida entre os eletrodos, cujos espaçamentos são previamente determinados, permitindo o cálculo de valores de resistividade $(\rho)$, para diferentes níveis de profundidade. A premissa principal é que a profundidade teórica de investigação é proporcional à distância de separação entre os eletrodos emissores de corrente $A B$, portanto, quanto maior a abertura, maior a profundidade investigada, atribuída ao ponto $O$ (Figura 2).

A interpretação nessa técnica consiste em definir um modelo geoelétrico em que as resistividades se relacionam com as propriedades geológicas, geotécnicas e hidrogeológicas do local (ORELLANA, 1972; TELFORD; GELDART; SHERIFF, 1990).

Foram realizadas $29 \mathrm{SEVs}$, dentro dos limites do cemitério, segundo uma malha semirregular, com o objetivo principal de determinar a profundidade do topo do nível de água subterrâneo, a fim de obter dados indicativos da direção do seu fluxo. Para tanto, o equipamento utilizado foi o resistivímetro Terrameter modelo SAS 4000, da ABEM Instruments (Suécia), e o dispositivo de campo empregado foi o Schlumberger.

Os resultados de campo foram submetidos a processamentos iniciais pelo software IX 1D v.3, INTERPEX Limited (Estados Unidos), e,

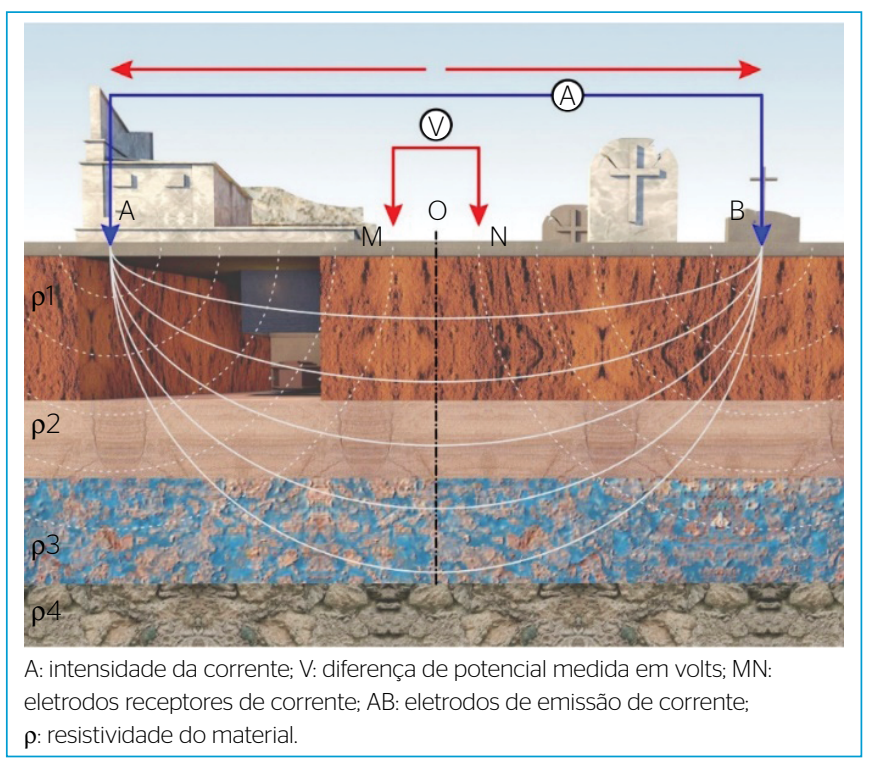

Figura 2 - Esquema simplificado da sondagem elétrica vertical. com base no conhecimento da geologia local, foram definidos os níveis ou estratos geoelétricos. Assim, pode-se identificar o topo do nível d'água para a posterior elaboração do mapa potenciométrico da área e a determinação do sentido do fluxo da água subterrânea por meio de um mapa de isovalores. As SEVs serviram também como referência para a alocação dos poços de monitoramento, em função do histórico de ocupação do cemitério.

\section{Poços de monitoramento, coletas e análises}

Após a elaboração dos modelos geoelétricos resultantes das SEVs e do levantamento do histórico de sepultamentos, foram locados e instalados cinco poços, nomeados de SPM1 a SPM5, na área de estudo. O cemitério foi ocupado inicialmente na porção nordeste da área, da frente para os fundos, no quadrante onde se encontram alocados os poços SPM2, SPM3 e SPM4. Tanto a localização das SEVs como a dos poços são mostradas na Figura 3.

Na sequência, foi realizada uma campanha de coleta de amostras de solos e água na área do cemitério, nos poços nas profundidades de $2 \mathrm{e}$ $16 \mathrm{~m}$, com objetivo de obter um diagnóstico inicial da presença de compostos contaminantes, por meio de análises químicas e microbiológicas.

As amostras de solo foram coletadas em duas profundidades; aprimeira, a aproximadamente $2 \mathrm{~m}$ de profundidade (profundidade máxima dos jazigos do cemitério); e a segunda, pouco antes das sondagens atingirem o nível d’água, na região denominada franja capilar.

Foram realizadas análises para sulfato, fosfato, cloreto, cálcio, ferro, potássio, sódio, série nitrogenada, bactérias heterotróficas, coliformes totais, coliformes termotolerantes e Clostridium perfringens, conforme normas técnicas estabelecidas pela CETESB (1999) para investigação confirmatória de contaminação subsuperficial.

Os parâmetros foram escolhidos dentre os contaminantes com maior probabilidade de ocorrerem na área, os que possuem maior toxidez e/ ou maior potencial para causar danos (CETESB, 1999).

Caso os resultados das análises realizadas indiquem valores superiores aos estabelecidos como limites para a área, esta poderá ser classificada como uma área contaminada (CETESB, 2001).

As coletas de água subterrânea ocorreram a uma profundidade aproximada de 16 metros. Conforme a CETESB (2005), os parâmetros físico-químicos e microbiológicos analisados na água subterrânea foram: temperatura, condutividade elétrica, oxigênio dissolvido e turbidez. Foram realizadas análises químicas para os parâmetros: cor aparente, sulfatos, fosfatos, cloretos, série nitrogenada (nitrogênio nítrico, nitrogênio nitroso, nitrogênio amoniacal, nitrogênio Kjeldahl, nitrogênio orgânico, nitrogênio albuminoide, nitrogênio total, contagem de bactérias heterotróficas, coliformes totais, coliformes termotolerantes, Clostridium perfringens, condutividade elétrica, temperatura, potencial de oxirredução (ORP), turbidez e oxigênio dissolvido. 


\section{RESULTADOS E DISCUSSÃO}

\section{Mapa potenciométrico}

A cota do topo do nível d'água que permite a verificação da orientação do fluxo de água subterrânea foi obtida a partir de modelos geoelétricos gerados pelas interpretações das SEVs que levaram à definição da superfície potenciométrica. A Figura 4 e a Tabela 1 apresentam uma curva característica da área do cemitério, com seu respectivo modelo geoelétrico apontando a espessura da cada camada geológica, bem como sua profundidade.

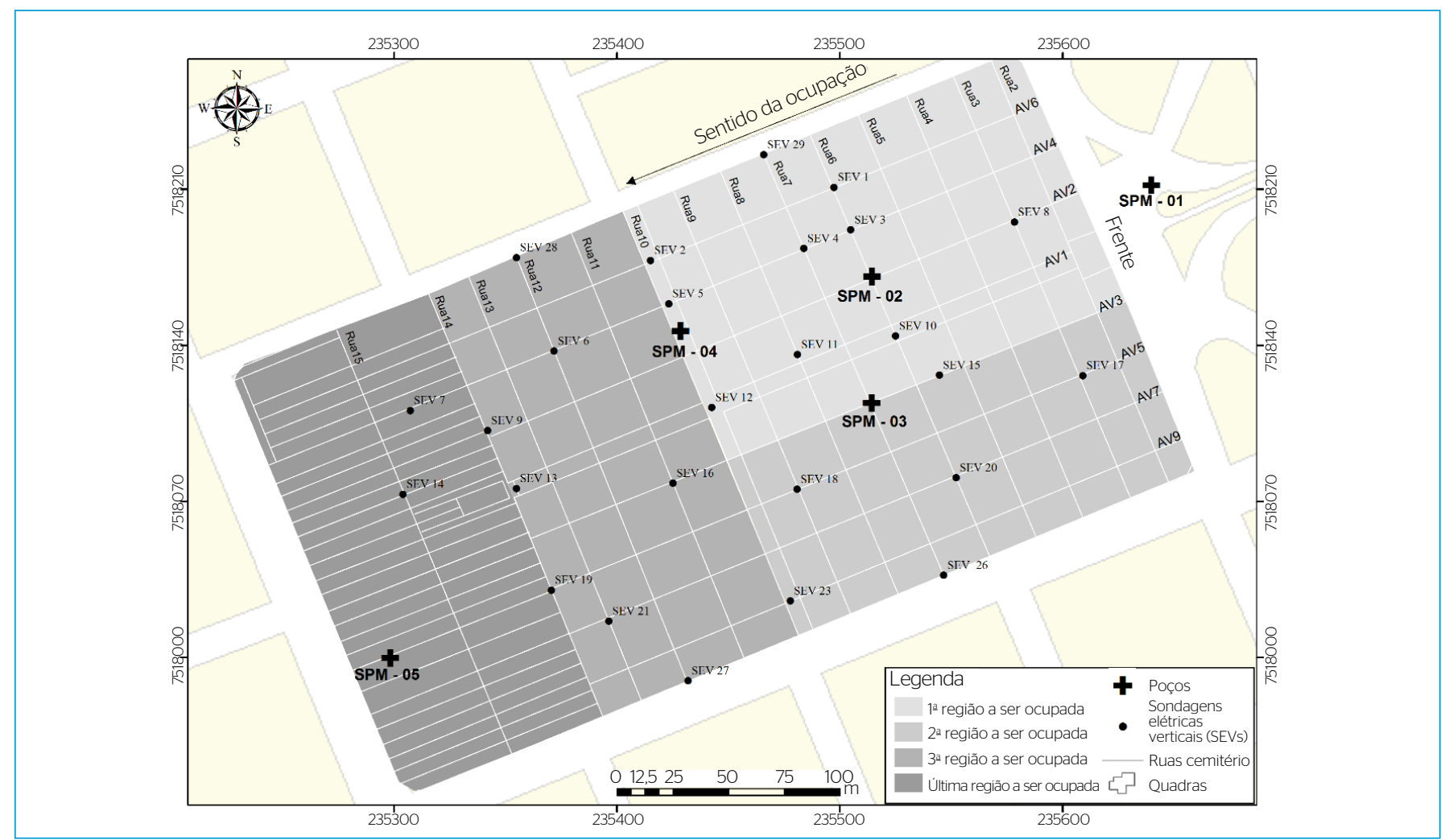

Figura 3 - Mapa de localização dos poços de monitoramento, das sondagens elétricas verticais e do histórico de ocupação.

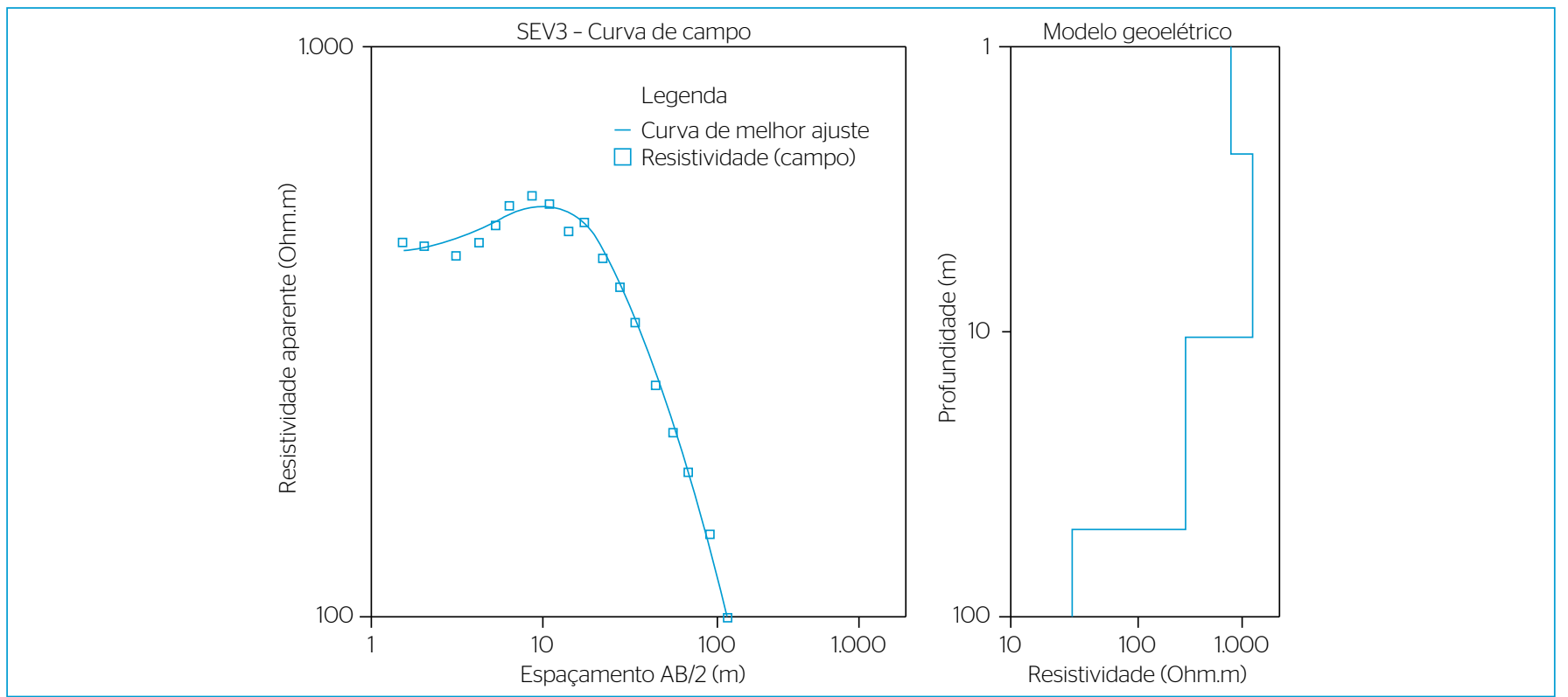

Figura 4 - SEV3: curva de campo interpretada. 
O fluxo subterrâneo do cemitério se orienta das cotas mais altas (região nordeste) para as cotas baixas (região sudoeste), e é condizente com a tendência regional da área conforme determinada anteriormente por Oliva (2006), e da porção de ocupação mais antiga do cemitério (frente) para a área de sepultamentos mais recentes (fundos) (Figura 5).

A direção do fluxo subterrâneo para o sudoeste do cemitério é condicionada pela diminuição da espessura da Formação Rio Claro,

Tabela 1 - Modelo geoelétrico de curva de campo interpretada.

\begin{tabular}{|c|c|c|c|c|}
\hline \multirow{2}{*}{$\begin{array}{l}\text { SEV3 } \\
\text { Nivel } \\
\text { geoelétrico }\end{array}$} & \multicolumn{3}{|c|}{ Cota: 603,8 m } & \multirow{2}{*}{$\begin{array}{c}\text { Descrição } \\
\text { dos materiais }\end{array}$} \\
\hline & $\begin{array}{l}\text { Resistividade } \\
\text { (Ohm.m) }\end{array}$ & $\begin{array}{l}\text { Espessura } \\
(\mathrm{m})\end{array}$ & $\begin{array}{c}\text { Profundidade } \\
(\mathrm{m})\end{array}$ & \\
\hline 1 & 496,7 & 0,5 & - & $\begin{array}{l}\text { Areia fina a } \\
\text { muito fina }\end{array}$ \\
\hline 2 & 150,8 & 2,0 & 0,5 & $\begin{array}{l}\text { Areia fina a } \\
\text { muito fina }\end{array}$ \\
\hline 3 & 43,8 & 8,1 & 2,5 & $\begin{array}{l}\text { Areia fina a } \\
\text { muito fina }\end{array}$ \\
\hline 4 & 30,2 & - & 10,6 & $\begin{array}{c}\text { Areia fina a } \\
\text { muito fina com } \\
\text { matriz argilosa }\end{array}$ \\
\hline
\end{tabular}

Nível freático: 10,6 m situando-se cada vez mais próxima ao contato com unidades subjacentes (argilitos e siltitos da Formação Corumbataí). Mais ao sul, o fluxo encontrará o córrego da Servidão, afluente do Rio Corumbataí, a aproximadamente 500 metros.

\section{Análises físico-químicas e microbiológicas em solos}

Cabe ressaltar que muitos parâmetros analisados não possuem valores de referência definidos pelos órgãos ambientais competentes como a Companhia Ambiental do Estado de São Paulo (CETESB) e o Ministério da Saúde. Portanto, os laboratórios disponibilizam os resultados, baseados no limite de quantificação (LQ), parâmetro de calibração definido por análises estatísticas, e as interpretações sobre possível contaminação devem estar associadas conjuntamente a outros estudos. A área será classificada como contaminada se houver constatação da presença de contaminantes no solo ou na água subterrânea acima dos referidos limites, e acima dos quais existem riscos potenciais diretos ou indiretos à saúde humana, considerada um cenário de exposição genérico.

Os resultados analíticos para solos no cemitério (Tabelas 2 e 3), de acordo com investigação confirmatória realizada pela Prefeitura de Rio Claro (2013), indicaram a presença, em todas as amostras, de valores alterados para nitrogênio orgânico, nitrogênio total pelo método Kjeldahl e nitrogênio total.

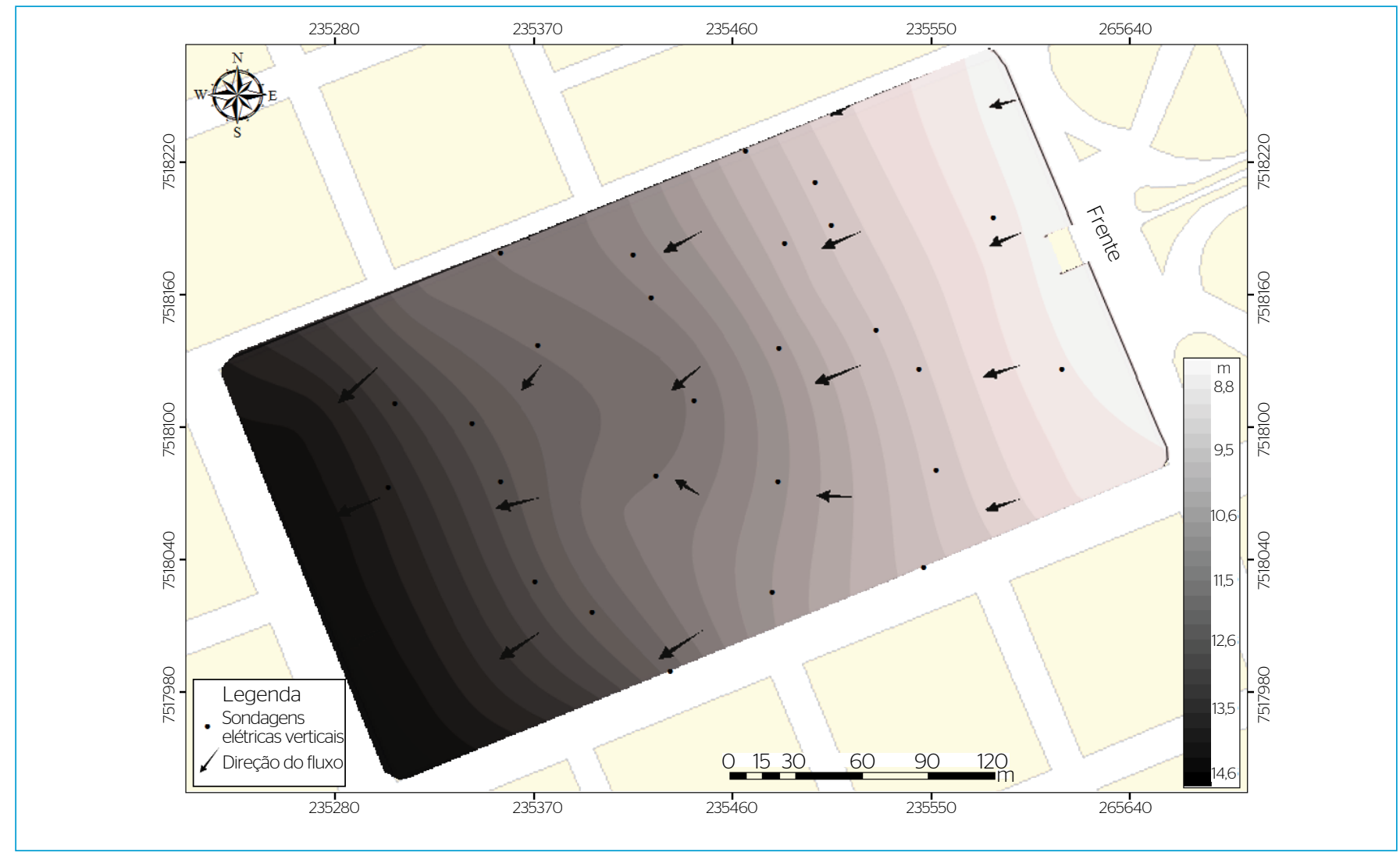

Figura 5 - Mapa potenciométrico do cemitério. 
O nitrogênio amoniacal foi encontrado nas amostras dos poços SPM1, SPM2 e SPM3. De acordo com a CETESB (2005), o nitrogênio pode ser encontrado nas formas de nitrogênio orgânico, amoniacal, nitrito e nitrato. As duas primeiras são formas reduzidas e as duas últimas, oxidadas. Podem-se associar às etapas de contaminação orgânica do meio a partir da relação entre as formas de nitrogênio.
Sabe-se que durante o processo de decomposição orgânica dos corpos, além dos líquidos liberados, há também a emissão de gases como a amônia e o amônio na solução do solo, principalmente quando a decomposição ocorre em ambiente anóxico. As substâncias nitrogenadas orgânicas oxidam até o nitrato. Dessa forma, a presença desse composto nitrogenado reduzido é indicativa de contaminação recente (MATOS, 2001).

Tabela 2 - Parâmetros analíticos de solos, com destaque para valores acima do limite de quantificação.

\begin{tabular}{|c|c|c|c|c|c|c|c|c|c|c|c|}
\hline Parâmetro & Unidade & \multicolumn{2}{|c|}{ SPM1/16m } & \multicolumn{2}{|c|}{$\mathrm{SPM} 2 / 2 \mathrm{~m}$} & \multicolumn{2}{|c|}{ SPM2/16m } & \multicolumn{2}{|c|}{$\mathrm{SPM} 3 / 2 \mathrm{~m}$} & \multicolumn{2}{|c|}{ SPM3/16m } \\
\hline Nitrato $(\mathrm{N})$ & $\mathrm{mg} / \mathrm{kg}$ & 0,173 & $<0,173$ & 0,167 & $<0,167$ & 0,170 & 0,858 & 0,168 & $<0,168$ & 5,0 & 72,83 \\
\hline Nitrogênio amoniacal & $\mathrm{mg} / \mathrm{kg}$ & 0,694 & 2,750 & 0,668 & 3,160 & 0,681 & $<0,681$ & 0,672 & 3,170 & 12,6 & $<12,60$ \\
\hline Nitrogênio orgânico & $\mathrm{mg} / \mathrm{kg}$ & 0,694 & 77,950 & 0,668 & 222,440 & 0,681 & 56,500 & 0,672 & 129,830 & 10,5 & 163,80 \\
\hline Nitrogênio total & $\mathrm{mg} / \mathrm{kg}$ & 0,173 & 80,700 & 0,167 & 225,600 & 0,170 & 57,400 & 0,168 & 133,000 & 18,9 & 180,40 \\
\hline Sulfato & $\mathrm{mg} / \mathrm{kg}$ & 5,300 & $<5,300$ & 5,000 & $<5,000$ & 5,200 & $<5,200$ & 5,100 & $<5,10$ & 5,1 & $<5,10$ \\
\hline Fosfato $(P)$ & $\mathrm{mg} / \mathrm{kg}$ & 0,347 & $<0,347$ & 0,334 & 0,450 & 0,341 & 0,360 & 0,336 & 0,392 & 0,2 & $<0,20$ \\
\hline Cloreto & $\mathrm{mg} / \mathrm{kg}$ & 5,300 & $<5,300$ & 5,000 & $<5,000$ & 5,200 & $<5,200$ & 5,100 & $<5,100$ & 5,1 & $<5,10$ \\
\hline Coliformes totais & NMP/gST & 0,300 & $<0,300$ & 0,300 & $<0,300$ & 0,300 & $<0,300$ & 0,300 & $<0,300$ & 0,3 & $<0,30$ \\
\hline C. perfringens & NMP/g & - & $<18,000$ & - & 330,000 & - & $<18,000$ & - & $<18,000$ & - & $<18,00$ \\
\hline
\end{tabular}

LQ: limite de quantificação (menor concentração do analito, que pode ser determinada com um nível aceitável de precisão e veracidade; também conhecido como limite de determinação, que corresponde ao padrão de calibração); NMP: número mais próximo; UFC: unidades formadoras de colônias; ST: sólidos totais.

Tabela 3 - Parâmetros analíticos de solos.

\begin{tabular}{|c|c|c|c|c|c|c|c|c|c|}
\hline \multirow{2}{*}{ Parâmetro } & \multirow{2}{*}{ Unidade } & \multicolumn{2}{|c|}{$\mathrm{SPM} 4 / 2 \mathrm{~m}$} & \multicolumn{2}{|c|}{ SPM4/16m } & \multicolumn{2}{|c|}{ SPM5/2m } & \multicolumn{2}{|c|}{ SPM5/16m } \\
\hline & & LQ & Resultado & LQ & Resultado & LQ & Resultado & LQ & Resultado \\
\hline Nitrato $(\mathrm{N})$ & $\mathrm{mg} / \mathrm{kg}$ & 0,167 & $<0,167$ & 5,0 & 11,805 & 0,167 & $<0,167$ & 0,173 & 5,270 \\
\hline Nitrogênio amoniacal & $\mathrm{mg} / \mathrm{kg}$ & 0,667 & $<0,667$ & 12,6 & $<12,600$ & 0,669 & $<0,669$ & 0,694 & $<0,694$ \\
\hline Nitrogênio orgânico & $\mathrm{mg} / \mathrm{kg}$ & 0,667 & 107,400 & 10,5 & 61,100 & 0,669 & 130,300 & 0,694 & 76,200 \\
\hline Nitrogênio total & $\mathrm{mg} / \mathrm{kg}$ & 0,167 & 107,400 & 18,9 & 63,800 & 0,167 & 130,300 & 0,173 & 81,500 \\
\hline Sulfato & $\mathrm{mg} / \mathrm{kg}$ & 5,000 & $<5,000$ & 5,0 & 40,000 & 5,000 & $<5,000$ & 5,100 & $<5,100$ \\
\hline Fosfato (P) & $\mathrm{mg} / \mathrm{kg}$ & 0,333 & 0,415 & 0,2 & $<0,200$ & 0,334 & 0,346 & 0,347 & 0,372 \\
\hline Cloreto & $\mathrm{mg} / \mathrm{kg}$ & 5,000 & $<5,000$ & 5,0 & $<5,000$ & 5,000 & $<5,000$ & 5,100 & $<5,100$ \\
\hline Coliformes totais & NMP/gST & 0,300 & $<0,300$ & 0,3 & $<0,300$ & 0,300 & 8,000 & 0,300 & $<0,300$ \\
\hline C. perfringens & NMP/g & - & $<18,000$ & - & 78,000 & - & 130,000 & - & $<18,000$ \\
\hline
\end{tabular}

LQ: limite de quantificação (menor concentração do analito, que pode ser determinada com um nível aceitável de precisão e veracidade; também conhecido como limite de determinação, que corresponde ao padrão de calibração); NMP: número mais próximo; UFC: unidades formadoras de colônias; ST: sólidos totais. 
A CETESB (1999) define que, em zonas de autodepuração natural, o nitrogênio orgânico é encontrado principalmente na zona de degradação, ou seja, na região em que ocorre possível contaminação recente; o nitrogênio amoniacal ocorre na zona de decomposição ativa; o nitrito, na zona de recuperação; e o nitrato, em locais considerados menos contaminados.

Os resultados analíticos de indicadores microbiológicos demonstraram a presença, principalmente, de bactérias heterotróficas em todos os poços do cemitério, acima do limite máximo de referência estipulado em 500 unidades formadoras de colônias por grama de sólidos totais (UFC/gST), tanto para solos quanto para água subterrânea, de acordo com o Ministério da Saúde (BRASIL, 2001).

Os microrganismos anaeróbios começam a substituir os organismos aeróbios dentro de poucas horas de morte do ser humano, desde que a temperatura predominante seja superior a

$5^{\circ} \mathrm{C}$. Começam a se multiplicar e, embora o intestino abrigue uma grande variedade de microrganismos, somente poucos grupos têm sido computados como importantes colonizadores de cadáveres humanos durante a putrefação (durante os primeiros dias após a morte), que são Clostridium perfringens, Streptococus e enterobactéricas (ÜÇISIK \& RUSHBROOK, 1998).

Para o parâmetro microbiológico Clostridium perfringens, os resultados analíticos demonstraram sua presença no meio poroso do solo nos poços SPM2, SPM4 e SPM5, com valores acima de 18 número mais próximo por grama $(\mathrm{NMP} / \mathrm{g})$, valor usado pelo LQ como referência. A Portaria no 36 do Ministério da Saúde (BRASIL, 1990) não faz menção aos outros parâmetros analisados neste estudo.

O poço SPM1 foi utilizado como background devido à sua localização (a montante do fluxo subsuperficial), porém, foram encontradas concentrações alteradas para compostos nitrogenados e bacteriológicos para bactérias heterotróficas.

Para o poço SPM2/2m, localizado próximo às SEVs 3 e 10, local em que se acredita ocorrerem as maiores alterações do meio físico pelo histórico de ocupação, foram verificadas alterações para os parâmetros bactérias heterotróficas e Clostridium perfringens, além de compostos nitrogenados (nitrogênio amoniacal, orgânico, Kjeldahl e total). O quadrante onde se localizam as SEVs supracitadas (Figura 3) representa o local mais antigo do cemitério, com presença de túmulos seculares, mas que ainda são utilizados. Portanto, a concentração de efluentes depositados em locais específicos contribui para as altas concentrações de alguns parâmetros bacteriológicos.

As amostras coletadas do poço SPM4/2m apresentaram valores alterados para compostos nitrogenados e bactérias heterotróficas em nível muito acima do limite de quantificação. Para as amostras coletadas no mesmo poço a uma profundidade de 16 metros, foi identificado o composto nitrato, o que permite concluir que se trata de uma região ainda conservada, porém com alguma influência do contaminante, devido à presença de compostos nitrogenados, baixa contagem de bactérias heterotróficas e Clostridium perfringens.

$\mathrm{Na}$ bibliografia, alguns trabalhos de análises de solos em áreas de cemitérios podem ser citados, como o de Charzynski, Bednarek e Zołnowska (2010), que correlacionou parâmetros químicos e físicos do solo do cemitério de Toruń, na Polônia, com solos fora da área contaminada. Identificaram grandes diferenças na estrutura, textura e composição química entre ambos; e o de Jonker \& Olivier (2012), que estudaram o cemitério de Zandfontein, em Tshwane, na África do Sul, e analisaram os solos do cemitério onde foram sepultados cerca de 60 mil caixões. Constataram excesso de metais pesados, de origem de práticas funerárias, e concluíram que os solos nas zonas com as cargas mais altas de sepultamentos eram mais contaminados do que nas partes menos utilizadas do cemitério e fora da área.

\section{Análises físico-químicas e microbiológicas em água subterrânea}

Em relação aos resultados da água subterrânea, de acordo com a CETESB (2001), nas zonas de autodepuração natural em rios, distinguem-se as presenças de nitrogênio orgânico na zona de degradação, amoniacal na zona de decomposição ativa, nitrito na zona de recuperação e nitrato na zona de águas limpas. Ou seja, se houver coleta de amostra de água de um local poluído e as análises demonstrarem predominância das formas reduzidas, isto é, nitrogênio orgânico e/ou amoniacal, indica que o foco de poluição se encontra próximo; se prevalecerem o nitrito e o nitrato, denota que as descargas de resíduos se encontram distantes. Além disso, a amônia provoca consumo de oxigênio dissolvido das águas naturais ao ser oxidada biologicamente, a chamada DBO de segundo estágio. Logo, se o amoniacal utiliza oxigênio disponível para seu processo de oxidação, ocorre uma diminuição do oxigênio dissolvido no meio.

Assim, de acordo com o histórico de ocupação do cemitério, utiliza-se esses critérios para a interpretação de locais com alterações mais concentradas, por possuir ocupações há mais tempo, e locais recentemente ocupados. Por esses motivos, a concentração de nitrogênio amoniacal é um importante parâmetro de classificação das águas naturais e é normalmente utilizado na constituição de índices de qualidade das águas.

De acordo com a Agência Nacional de Águas (ANA), os nitratos são tóxicos, podendo causar uma doença chamada metahemoglobinemia infantil, letal para crianças (o nitrato reduz-se a nitrito na corrente sanguínea, competindo com o oxigênio livre, tornando o sangue azul). Por isso, o nitrato é padrão de potabilidade, sendo $10 \mathrm{mg} \cdot \mathrm{L}^{-1} \mathrm{o}$ valor máximo permitido pela Portaria nº 2.914 do Ministério da Saúde (BRASIL, 2011).

Entre os paramentos analisados em água subterrânea no cemitério (Tabela 4), apenas o nitrato (N) apresenta valor de intervenção (VI) estabelecido pela CETESB (2005), sendo esse, de $10 \mathrm{mg} \cdot \mathrm{L}^{-1}$. Dessa forma, 
os poços SPM2 e SPM3 apresentaram concentrações acima do VI, sendo as mesmas de 18,723 e 13,569 mg. $\mathrm{L}^{-1}$, respectivamente.

Os resultados obtidos apontam também grande atividade biológica na área, sendo esta constatada diretamente por meio dos parâmetros "contagem de bactérias heterotróficas" e indiretamente pelos parâmetros "concentração de oxigênio dissolvido" e pH (Tabela 4).

Na contagem de bactérias heterotróficas, os resultados nos poços SPM2, SPM3, SPM4 e SPM5 apareceram maiores que o limite máximo

Tabela 4 - Parâmetros analíticos de água subterrânea.

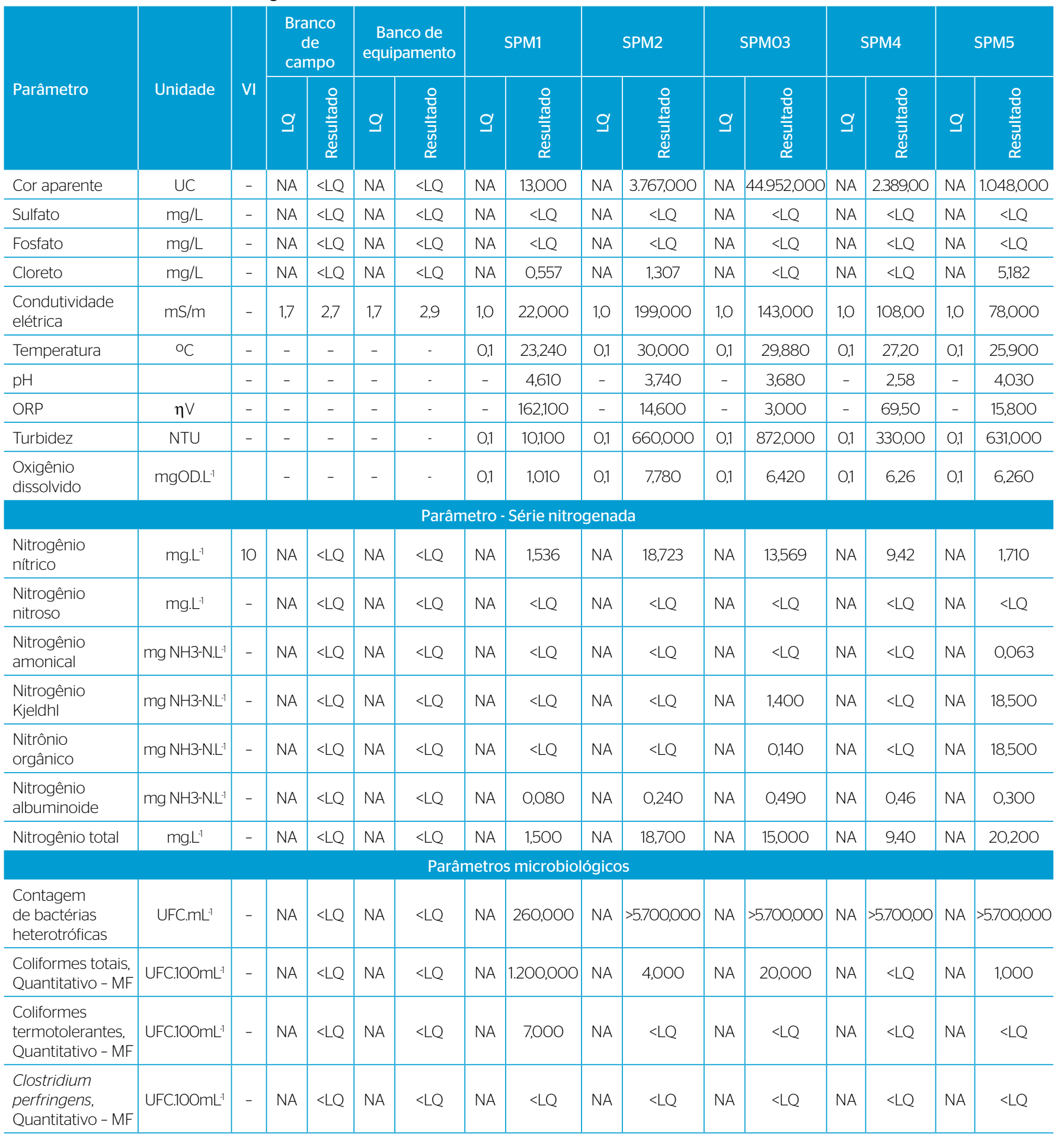

VI: valor de intervenção; LQ: limite de quantificação (menor concentração do analito, que pode ser determinada com um nível aceitável de precisão e veracidade; também conhecido como limite de determinação, que corresponde ao padrão de calibração); UC: unidade de cor; NA: não avaliado; $\eta$ V: milivolts; NTU: unidades nefelométricas de turbidez; OD: oxigênio dissolvido; MF: método da membrana filtrante; UFC: unidades formadoras de colônias. 
de quantificação (>5.700 UFC. $\left.100 \mathrm{~mL}^{-1}\right)$, indicando a presença desses microrganismos no meio.

Foi observado também o aumento da concentração de íons $\mathrm{H}^{+}$, que reflete a redução do $\mathrm{pH}, \operatorname{logo}$, acidificação do meio. Essa redução pode ser observada nos poços SPM2 a SPM5 quando comparados com o SPM1, localizado a montante do fluxo subterrâneo e área externa ao cemitério, sendo o menor $\mathrm{pH}$, no SPM4, com valor de 2,58 no local onde se acredita ocorrer alteração do meio pela ocupação mais antiga do cemitério (Tabela 4).

Segundo Migliorini (1994) e Matos (2001), a presença de necrochorume provoca um acréscimo na quantidade de sais minerais que, além de elevar a condutividade elétrica do meio, leva a um aumento da concentração de íons como cloretos e compostos nitrogenados.

As concentrações de nitrogênio nítrico mais elevadas nos poços SPM2, SPM3 e SPM4, locais de alterações do meio físico detectado pelos ensaios geofísicos, também coincidem com os pHs mais baixos nesses poços, sendo outro indicativo de acidez do meio. Além disso, as concentrações de oxigênio dissolvido nas amostras de água coletadas são favoráveis à atividade microbiológica de nitrificação.

Marinho (1998) encontrou produtos nitrogenados nas águas subterrâneas do cemitério São João Batista, em Fortaleza, no Ceará.

Migliorini (1994) também encontrou concentrações elevadas de $\mathrm{NH}_{4}^{+}$(nitrito) e $\mathrm{NO}_{3}$ (nitrato) no cemitério de Vila Formosa, em São Paulo, provenientes do processo de decomposição dos corpos que produz diaminas, como a cadaverina $\left(\mathrm{C}_{5} \mathrm{H}_{14} \mathrm{~N}_{2}\right)$ e a putrescina $\left(\mathrm{C}_{4} \mathrm{H}_{12} \mathrm{~N}_{2}\right)$, e podem ser degradadas, gerando $\mathrm{NH}_{4}^{+}$. No cemitério de Vila Nova Cachoeirinha, o autor concluiu que as águas mais próximas da superfície apresentam menor quantidade de oxigênio dissolvido do que as águas mais profundas. Naquele ambiente redutor, nitrogênio orgânico e amônio são mais estáveis, como foi observado em efluente de fossa séptica no Parque Ecológico do Tietê, em São Paulo (VARNIER \& HIRATA, 2000).

Para a análise de contaminação por necrochorume na área do cemitério, o pressuposto foi que as maiores concentrações desse composto estariam localizadas em menores profundidades, principalmente pela profundidade do nível basal dos jazigos, localizados a 2 metros de profundidade, a partir de onde se inicia a percolação do efluente ao meio poroso. Assim, as análises do meio poroso do solo são mais representativas.

Portanto, locais ocupados inicialmente, dentro do período de 130 anos, que ainda se mantém ativos, são locais potencialmente mais alterados fisicamente, com maiores concentrações do efluente.

No cemitério em estudo, o extravasamento de necrochorume é comum, e foi flagrado em algumas situações (Figura 6). Esses estágios de extravasamento ocorrem aproximadamente em 20 a 30 dias após o sepultamento, de acordo com as datas nos túmulos, e das condições climáticas do município, como pluviosidade no período do sepultamento, por exemplo.
Com mais de 130 anos de atividade, foram realizados muitos sepultamentos com retiradas de ossadas e substituições por novos cadáveres, que novamente contribuíram com efluentes contaminantes para a alimentação do substrato. Esse processo representa uma fonte pontual de contaminação, e mesmo que ocorra um processo de atenuação natural, são necessários de 2,5 a 3 anos para que o substrato volte a se renovar, sem deposição de novos cadáveres (MATOS, 2001), o que ainda não foi o caso, pois o cemitério continua ativo.

Silva, Malagutti Filho e Moreira (2009) realizaram estudo de áreas potencialmente impactadas por necrochorume no cemitério municipal de Vila Rezende, Piracicaba, São Paulo. Foi concluído que as plumas de contaminação têm ligação com a profundidade do nível freático e com o tempo de sepultamento.

De acordo com informações concedidas pelos funcionários, existem mais de 12 mil túmulos no cemitério de Rio Claro, e mais de 200 mil pessoas enterradas.

\section{CONCLUSÕES}

A dificuldade de identificação e quantificação de fontes difusas de contaminação que envolvem o lançamento dos poluentes de forma variável no tempo e espaço permite a configuração de hipóteses diversas. Métodos diretos de investigação, como as análises dos poços associadas com métodos indiretos de investigação, como os ensaios geofísicos, apresentam geralmente resultados relevantes para as mais variadas pesquisas.

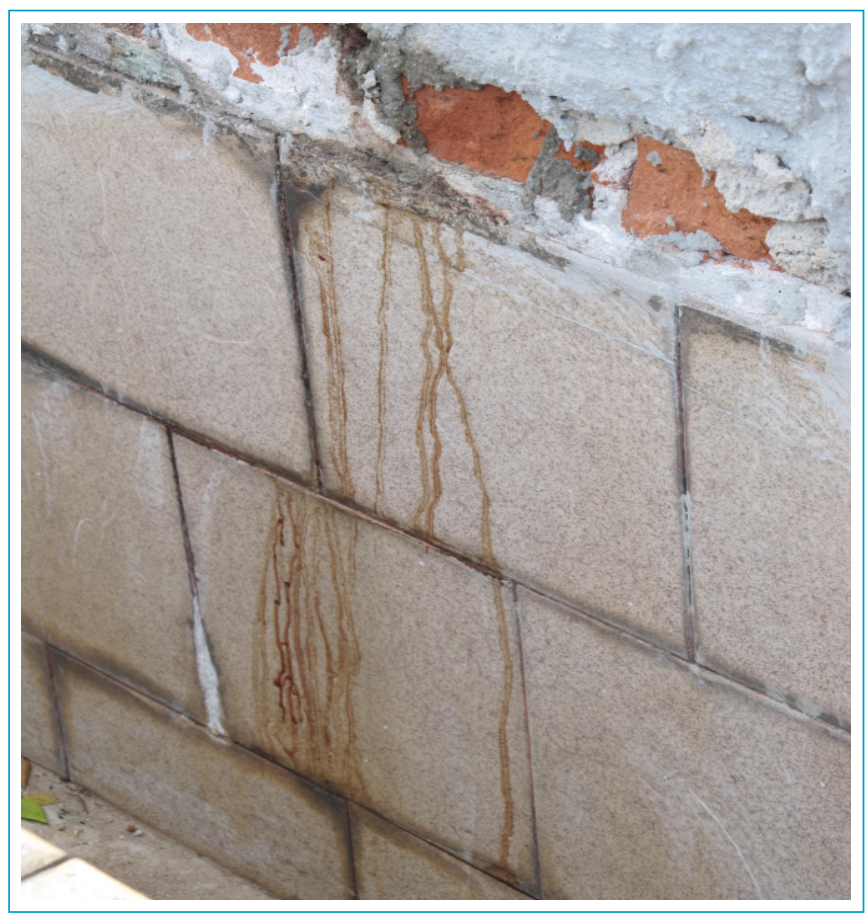

Figura 6 - Extravasamento de necrochorume no túmulo no Cemitério Municipal de Rio Claro, São Paulo. 
Os resultados das análises químicas para o meio subsuperficial na área do cemitério apresentaram resultados positivos, com indícios de contaminação do meio poroso, principalmente a $2 \mathrm{~m}$ de profundidade, local imediatamente abaixo do nível máximo de profundidade dos jazigos, onde se inicia a percolação do efluente.

Os resultados analíticos de água e solos dos poços foram coerentes com as suposições de contaminação nas áreas mais antigas do cemitério, ou seja, ocupadas desde o fim do século XIX - e, portanto, com maior número de sepultamentos. Foram encontrados valores alterados onde se concentra boa parte dos túmulos mais antigos e também jazigos familiares com reposição de cadáveres ainda ativo, região essa, secular.

As características da geologia local contribuem para a percolação do efluente por se tratar de um meio altamente permeável, característica dos arenitos da Formação Rio Claro. Esse tipo litológico, de acordo com Matos (2001), permite a infiltração de material contaminante em velocidades muito maiores do que as que ocorrem em meio argiloso. Porém, o mesmo autor ressalta que as propriedades físico-químicas do solo permitem que o mesmo tenha capacidade de depuração natural dos contaminantes, e que a capacidade de retenção no solo mantém uma relação inversa com a permeabilidade do solo. Assim, ao infiltrar o contaminante, infiltram também microrganismos responsáveis pela evolução do mesmo.

Como o cemitério ainda se mantém ativo, recomenda-se, além da interrupção da atividade, a contenção das plumas por meio de filtros instalados nos poços de monitoramento com objetivo de evitar o extravasamento destas para além dos limites subterrâneos do cemitério.

\section{REFERÊNCIAS}

AMUNO, S.A.; AMUNO, M.M. (2014) Spatio-temporal variation of trace element contentes in Rwanda necrosols. Environment Earth Science, v. 71, p. 659-674.

BRASIL. (1990) Ministério da Saúde. Portaria no 36, de 19 de janeiro de 1990. Aprova novas normas e padrões de potabilidade da água a serem observados em todo território nacional. Diário Oficial da República Federativa do Brasil, Brasília.

(2001) Ministério da Saúde. Portaria no 1.469, de 29 de dezembro de 2000. Estabelece os procedimentos e responsabilidades relativos ao controle e vigilância da qualidade da água para consumo humano e seu padrão de potabilidade, e dá outras providências. Diário Oficial da República Federativa do Brasil, Brasília.

(2011) Ministério da Saúde. Portaria no 2.914, de 12 de dezembro de 2011. Dispõe sobre os procedimentos de controle e de vigilância da qualidade da água para consumo humano e seu padrão de potabilidade. Diário Oficial da República Federativa do Brasil, Brasília.

CHARZYNSKI, P.; BEDNAREK, R.; ZOŁNOWSKA, B. (2O10) Characteristics of the soils of Torun cemeteries. In: WORLD CONGRESS OF SOIL SCIENCE, SOIL SOLUTIONS FOR A CHANGING WORLD, 19., 2010, Brisbane, Austrália. Anais... Brisbane.

COMPANHIA AMBIENTAL DO ESTADO DE SÃO PAULO (CETESB). (1999) Implantação de Cemitérios: Norma Técnica L1. O4O. São Paulo: CETESB.

(2001) Manual de gerenciamento de áreas contaminadas. 2 ed. Projeto CETESB-GTZ, Cooperação Técnica Brasil-Alemanha. São Paulo: CETESB. Disponível em: <https://pt.scribd.com/ doc/50743939/Manual-Cetesb-Integral>. Acesso em: nov. 2014.

(2005) Valores orientadores para solos e águas subterrâneas no Estado de São Paulo. São Paulo: CETESB. Disponível em: <http:// cetesb.sp.gov.br/solo/valores-orientadores-para-solo-e-aguasubterranea/>. Acesso em: nov. 2014.

DENT, B.B.; KNIGHT, M.J. (1995) A watery grave: the role of hydrogeology in cemetery practice. Australian Cemeteries \& Crematoria Association News, v. 2, p. 19-22.

DENT, B.B.; KNIGHT, M.J. (2007) Cemeteries: a special kind of landfill: the context of their sustainable management. Australia: National Centre for Groundwater Management, University of Technology, Sydney Broadway.

JONKER, C:; OLIVIER, J. (2012) Mineral contamination from cemetery soils: case study of Zandfontein Cemetery, South Africa. International Journal of Environmental Research and Public Health, n. 9. p. 511-520. DOI: 10.3390/ijerph9020511

MARINHO, A.M.C.P. (1998) Contaminação de aquiferos por instalação de cemitérios. Estudo do caso do Cemitério São João Batista, Fortaleza - Ceará. Dissertação (Mestrado) - Centro de Ciências, Departamento de Geologia, Universidade Federal do Ceará, Fortaleza.

MATOS, B.A. (2001) Avaliação da ocorrência e do transporte de microrganismos no aquifero freático do cemitério de Vila Nova Cachoeirinha, município de São Paulo. 115 p. Tese (Doutorado) Instituto de Geociências, Universidade de São Paulo, São Paulo.

MATOS, B.A.; PACHECO, A. (2002) Avaliação da ocorrência e do transporte de microrganismos no aquífero freático do cemitério de Vila nova cachoeirinha, município de são Paulo. In: CONGRESSO BRASILEIRO DE ÁGUAS SUBTERRÂNEAS, 11., 2002, Florianópolis. Anais... Florianópolis: ABAS.

MIGLIORINI, R.B. (1994) Cemitérios como fontes de poluição em aquíferos. Estudo do Cemitério Vila Formosa na bacia sedimentar de São Paulo. 74 p. Dissertação (Mestrado em Recursos Minerais e Hidrogeológicos), Instituto de Geociências, Universidade de São Paulo, São Paulo. da USP. 
OLIVA, A. (2006) Estudo hidrofaciológico do aquífero Rio Claro no município de Rio Claro - SP. 196p. Tese (Doutorado) - Instituto de Geociências e Ciências Exatas, Universidade Estadual Paulista "Júlio de Mesquita Filho", Rio Claro.

ORELLANA, E. (1972) Prospección geoeléctrica en corriente continua. Biblioteca Tecnica Philips, Madri: Paraninfo. 523p.

PACHECO, A.; MENDES, J.M.B.; MARTINS, M.T.; HASSUDA, S.; KIMMELMANN, A.A. (1991) Cemeteries: a potential risk to groundwater. Water Science and Technology, Great Britain, v. 24 , n. 11, p. $97-104$

POUNDER, D.J. (1995) Postmortem changes and time of death. In: REIS, J.J. A morte é uma festa. São Paulo: Companhia das Letras. $357 \mathrm{p}$.

PREFEITURA DE RIO CLARO. (2013) Investigação ambiental confirmatória Cemitério São João Batista. Relatório Técnico Geocia. Rio Claro: Prefeitura de Rio Claro. 63 p.

REZENDE, E.C.M. (2005) Necrochorume. Salve o Planeta Terra. Disponível em: <http://salveomundo.blogspot.com.br/2005/05/ necrochorume.html/>. Acesso em: ago. 2013.

SILVA, L.M. (1995) Os Cemitérios na Problemática Ambiental. In: SEMINÁRIO NACIONAL CEMITÉRIOS E MEIO AMBIENTE, 1., 1995. Anais... São Paulo: SINCESP e ACEMBRA. 148 p.

(1998) Cemitérios: fonte potencial de contaminação dos aquíferos livres. In: CONGRESSO LATINO AMERICANO DE HIDROLOGIA SUBTERRÂNEA, 4., 1998. Memórias. Montevideo: ALHSUD. v. 2, p. 667-681.
SILVA, R.W.C.; MALAGUTTI FILHO, W.; MOREIRA, C.A. (2009) Emprego do método da eletrorresistividade no estudo da contaminação subterrânea do cemitério municipal de Vila Rezende, Piracicaba - SP. Revista Brasileira de Geofísica, Rio de Janeiro, v. 27, n. 3, p. 389-399.

SPONGBERG, A.L.; BECKS, P.M. (2000) Inorganic soil contamination from cemetery leachate. Water, Air and Soil Pollution, v. 117, n. 1-4, p.313-327. DOI: 10.1023/A:1005186919370

TELFORD, W.M.; GELDART, L.P.; SHERIFF, R.E. (1990) Applied Geophysics. 2. ed. Cambridge: Cambridge University Press. 744 p.

ÜÇISIK, A.S.; RUSHBROOK, P. (1998) The impact of cemeteries on the environment and public health: an introductory briefing. Dinamarca: WHO. Disponível em: <http://apps.who.int/iris/ bitstream/10665/108132/1/EUR_ICP_EHNA_01_O4_01\%28A\%29. pdf>. Acesso em: set. 2012

VARNIER, C.; HIRATA, R. (2000) Contaminação da água subterrânea por nitrato no Parque Ecológico do Tietê - São Paulo, Brasil. In: CONGRESSO MUNDIAL INTEGRADO DE ÁGUAS SUBTERRÂNEAS, 1., 2000, Fortaleza. Anais... Fortaleza: ABAS. 1 CD-ROM.

ZAINE, J.E. (1994) Geologia da Formação Rio Claro da folha de Rio Claro (SP). 134 f. Dissertação (Mestrado em Geociências) - Instituto de Geociências e Ciências Exatas, Universidade Estadual Paulista "Júlio de Mesquita Filho", Rio Claro.

ZYCHOWSKI, J.; BRYNDAL, T. (2015) Impact of Cemeteries on Groundwater contamination by Bacteria and Viruses - A Review. Journal of Water and Health, v. 13, n. 2, p. 285-301. DOI: 10.2166/ wh.2014.119 